\title{
APLICAÇÃO DE DADOS AEROGEOFÍSICOS NO MAPEAMENTO GEOLÓGICO DO LIMITE ENTRE OS TERRENOS ARQUEANOS E PROTEROZÓICOS DA REGIÃO DE CRIXÁS-CEDROLINA, GOIÁS
}

\author{
MARCELO DE LAWRENCE BASSAY BLUM, ADALENE MOREIRA SILVA, HARDY JOST, PAULO ROBERTO MENESES, \\ REINHARDT ADOLFO FUCK, JOSÉ AFFONSO BROD, ALEXANDRE DE AMORIM TEIXEIRA, ALEXANDRE AUGUSTO \\ CARDOSO DA SILVA, ANDRÉ LUIZ DURANTE SPIGOLON, MARCOS VINICIUS RODRIGUES MAAS, MICHELLE MOTA \\ DE SOUZA, PEDRO MACEDO JÚNIOR, BRUNO EUSTÁQUIO MOREIRA LIMA \& MARINA DE OLIVEIRA CAMPOS
}

\begin{abstract}
AIRBORNE GEOPHYSICAL DATA APPLIED TO GEOLOGICAL MAPPING OF THE ARCHAEAN - PROTEROZOIC BOUNDARY, CRIXÁS-CEDROLINA REGION, GOIÁS, BRAZIL This paper presents an integrated approach to geological mapping, by the use of old airborne geophysical data. The data processing and interpretation allowed the use of the Brazil - Canada Geophysical Project for much more comprehensive understanding of the regional and local geology. The interpretation of airborne magnetics has provided both an overview of the regional structure as well as further insights into the structural controls of the Crixás-Cedrolina region. The four radiometric maps (total count, potassium, uranium and thorium) were individually enhanced by manipulation of their histograms and then displayed in pseudo-color, as ternary displays $(\mathrm{R}: \mathrm{G}: \mathrm{B}=\mathrm{K}: \mathrm{Th}: \mathrm{U})$. Individual lithological units can be traced due to their distinctive radiometric response. Ground magnetics profile provided good results identifying detailed location for the boundary. This kind of approach is fundamental for investigating the regional structural framework and helps to better define the boundaries of the different lithostratigraphic units present in Precambrian terranes.

Keywords: geological mapping, airborne geophysical data, Archean and Proterozoic terranes

RESUMO Este artigo mostra uma aplicação de dados acrogeofísicos de baixa resolução para mapeamento geológico. Estes dados foram interpretados com ênfase no contexto geológico proporcionando uma melhor compreensão da geologia regional e local. A interpretação de dados magnéticos forneceu tanto uma visão geral da arquitetura regional, bem como uma melhor compreensão dos controles estruturais do limite entre os terrenos arqueanos e proterozóicos da região de Crixás-Cedrolina. Os quatro mapas radiométricos (contagem total, potássio, urânio e tório) foram realçados individualmente pela manipulação de seus histogramas e, posteriormente, apresentados em falsa cor e na forma de imagens ternárias ( $\mathrm{R}: \mathrm{G}: \mathrm{B}=\mathrm{K}: \mathrm{Th}: \mathrm{U})$. Diferentes unidades litológicas podem ser traçadas, uma vez que possuem resposta radiométrica distinta. Perfil magnético terrestre permitiu boa identificação do limite entre os terrenos. Este tipo de abordagem é fundamental na investigação do arcabouço estrutural, bem como na definição de contatos e limites litoestratigráficos em terrenos pré-cambrianos.
\end{abstract}

Palavras-chaves: mapeamento geológico, dados geofísicos aéreos, terrenos arqueanos e proterozóicos

INTRODUÇÃO Projetos geofísicos regionais representam um grande avanço nas perspectivas para o setor mineral e excelente ferramenta para mapeamentos geológicos (Jaques et al. 1997, Silva 1999, Blum 1999). O Projeto Geofísico Brasil-Canadá (PGBC), realizado cm meados de 1970, cobriu cerca de $780 \mathrm{mil} \mathrm{km}^{2}$ e durante o qual foram adquiridos dados aeromagnetométricos e aerogamaespectrométricos, complementados por levantamentos geofísicos e geoquímicos terrestres. O objetivo deste artigo é demonstrar que dados aerogeofísicos foram ferramentas importantes durante o mapeamento geológico do limite entre os terrenos arqueanos e proterozóicos da região situada entre Crixás e Cedrolina, no Estado de Goiás. Os dados aerogeofísicos do PGBC (Fig. 1) cobrem a área de estudo e seu entorno, e foram for-

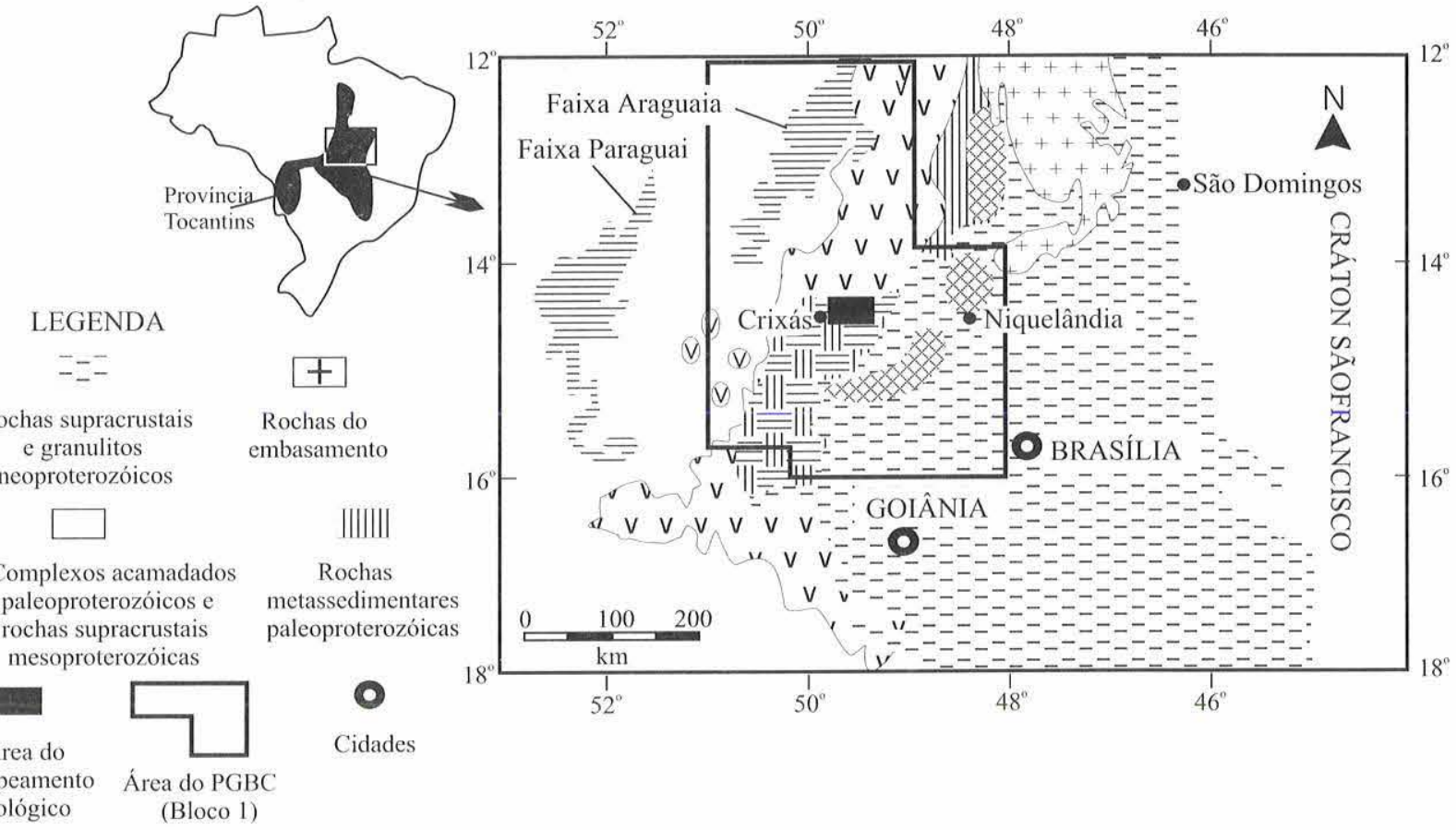

Figura I - Localizaşão geográfica do Projeto Geofísico Brasil-Canadá, ilustrando a área do bloco I. estudada de forma regional por Blum (1999). e localização do mapa geológico da região estudada. 
necidos pela CPRM em formato digital ASCII, tipo XYZ, distribuídos em 8 arquivos, cada qual correspondendo a uma carta magnética ou gamaespectrométrica em escala 1:100.000. Estes dados fazem parte do bloco 1 e foram processados e interpretados por Blum (1999) em escala 1:250.000.

CONTEXTO GEOLógico A área mapeada situa-se no centrosul da Província Tocantins (Fig. 1), abrangendo parte da região setentrional dos terrenos arqueanos e meridional dos terrenos neoproterozóicos do Arco Magmático de Mara Rosa (Jost et al. 2001, Dantas et al. 2001). Rochas arqueanas afloram na metade sul da área estudada e compreendem, de oeste para leste, parte dos greenstone belts de Crixás, Guarinos e Pilar de Goiás, e associaçōes granitognáissicas de parte do Complexo Caiamar e do Bloco Moquém. As rochas do Proterozóico ocorrem na metade norte da área e consistem, de oeste para leste, de uma unidade metassedimentar tectonicamente sobreposta à outra, de natureza metavulcânica, por sua vez dividida em três escamas de empurrão que diferem em grau metamórfico, associação litológica e padrão estrutural (ver Jost et al. 2001). O contato entre os segmentos arqueano e proterozóico é a Zona de Cisalhamento Mandinópolis. Ambos segmentos contém restos de crostas ferruginosas, depósitos de canais fluviais suspensos e planícies aluviais.

Os greenstone belts de Crixás, Guarinos e Pilar de Goiás compreendem estreitas faixas orientadas segundo N-S e estão separados, respectivamente, por rochas do Complexo Caiamar e do Bloco Moquém. $\mathrm{Na}$ área mapeada, as rochas diagnósticas dos greenstone belts compreendem metakomatiitos, metabasaltos komatíticos, metabasaltos e rochas metassedimentares detríticas (filitos carbonosos), subordinadamente químicas (rochas cálcio-silicáticas, mármores, formações ferríferas e manganesíferas e metachert). As rochas metavulcânicas ultramáficas e máficas e as metassedimentares ocorrem em faixas independentes, justapostas por contato normal ou tectônico. Rochas metassedimentares químicas, particularmente formações ferríferas e manganesíferas e metachets, ocorrem como intercalações lenticulares nas metavulcânicas e em xistos carbonosos, como imbricações na falha em contato com o greenstone belt de Pilar de Goiás e o Bloco Moquém, ou nos metakomatiitos de Pilar de Goiás. No greenstone belı de Guarinos, os metabasaltos estão parcialmente interrompidos pela intrusão do Trondhjemito Santo Antônio.

Dentre as associações granito-gnáissicas, o Complexo Caiamar, situado entre os greenstone belts de Crixás e Guarinos, consiste dos Gnaisses Crixás Açu, de composição tonalítica, e do Tonalito Tocambira, ambos com eventuais diques máficos anfibolitizados. O Bloco Moquém se situa entre os greenstone belts de Guarinos e Pilar de Goiás e consiste de gnaisses granodioríticos e tonalíticos e localmente migmatitos. Esses gnaisses estão intrudidos, na porção norte, por stocks máficos e ultramáficos, no sul por enxame de diques anfibolitizados e, no extremo sul, por dois stocks tonalíticos.

As rochas do Proterozóico ocorrem na metade norte da área mapeada e estão reunidas $\mathrm{em}$ uma unidade metassedimentar e outra metavulcânica (Jost et al. 2001). A unidade metassedimentar ocorre em duas áreas, uma situada no terço noroeste e outra na porção centronorte da área mapeada e ambas estão tectonicamente sobrepostas a rochas da unidade metavulcânica. A unidade metavulcânica ocorre ao longo da metade norte-leste da área e seus litotipos estão reunidos $\mathrm{cm}$ três escamas de empurrão que se ordenam, de oeste para leste, de posições estruturais superiores para as inferiores, sob a denominação de Escamas A, B e C. A escama A consiste de anfibolitos e anfibólio xistos derivados de basaltos e andesitos, com eventuais lentes de quartzo-mica xistos e quartzitos micáceos, metamorfizados na fácies anfibolito. A escama B consiste de clorita xistos, por vezes ricos em magnetita, interpretados como prováveis tufos e derrames andesíticos, nos quais se intercalam eventuais biotita xistos e gnaisses quartzofeldspáticos de composição dacítica a riodacítica, metamorfizados na fácies xisto verde. A escama $\mathrm{C}$ é litologicamente similar à escama $\mathrm{B}$, exceto pela maior abundância de quartzo, raridade de magnetita em clorita xistos e freqüentes intercalações de quartzito e metarritmito.

NATUREZA DOS DADOS ESTUDADOS A base de dados aerogeofísicos que subsidiou o mapeamento da área estudada provém dos levantamentos aéreos realizados durante o Projeto Geofísico Brasil - Canadá (PGBC) (Fig. 1). Durante o mapeamento também foi realizado um levantamento magnético terrestre.

Projeto Geofísico Brasil - Canadá O PGBC resultou de convênio entre o Ministério das Minas e Energia (MME) e a Agência Canadense para o Desenvolvimento Internacional (Canadian International Development Agency - CIDA), e visou subsidiar o levantamento dos recursos minerais da região Centro-Oeste entre as latitudes $5^{\circ} \mathrm{S}$ e $16^{\circ} \mathrm{S}$ e os meridianos $48^{\circ} \mathrm{W}$ e $51^{\circ} \mathrm{W}$. O aerolevantamento cmpregou magnetometria e gamaespectrometria, com linhas de produção espaçadas em $2 \mathrm{~km}$ segundo $\mathrm{N}$-S verdadeiro e linhas de controle E-W espaçadas $\mathrm{cm} 14 \mathrm{~km}$. Cerca de $30 \%$ da área foi detalhada com linhas de vôo N-S espaçadas em 1 km (Fig. 1, Carmo 1978, DNPM 1981).

A plataforma utilizada consistiu de aeronaves DC-3 que voaram a $220 \mathrm{~km} / \mathrm{h}$ e altura de $150 \mathrm{~m}$, com tolerância de $\pm 10 \%$ em regiões de topografia suave e de $\pm 50 \% \mathrm{em}$ acidentadas. O controle da altura realizou-se mediante radar altímetro com leitura a cada segundo. A navegação foi controlada por sistema Doppler e recuperada a partir de fotografias colhidas durante o vôo com câmeras fotográficas de $35 \mathrm{~mm}$ (DNPM 1981).

As medidas de intensidade de campo magnético total foram obtidas com magnetômetro do tipo Fluxgate, com sensor montado em esporão na cauda da aeronave $\mathrm{c}$ a correção de campos espúrios compensados eletronicamente. As medidas foram registradas aproximadamente a cada $70 \mathrm{~m}$ com precisão de $\ln \mathrm{T}$ ( 1 nanoTesla $=10^{-9} \mathrm{~T}=1$ gamma). Os dados gamaespectrométricos foram adquiridos com espectrômetro diferencial equipado com detectores de Iodeto de Sódio ativados por Tálio $[\mathrm{Nal}(\mathrm{Tl})]$ e o espectro amostrado correspondeu ao das janelas de energia de contagem total $(0,4-2,81 \mathrm{MeV})$, Potássio $(1,37-1,57$ $\mathrm{MeV})$, Urânio (1,66 - 1,86 MeV) e Tório $(2,41-2,81 \mathrm{MeV})$.

Magnetometria Terrestre Os perfis magnéticos terrestres foram efetuados com emprego de magnetômetro de precessão de prótons, modelo G-856 da Geometrics. Os dados foram corrigidos quanto a variação diurna do campo geomagnético, reduzidos do Definitive Geomagnetic Reference Field (DGRF - 2000) e filtrados para minimizar os efeitos de ruído branco (filtro não-linear sem tolerância). A partir do campo anômalo resultante foi calculada a amplitude do sinal. Os perfis foram orientados, na medida do possível, transversalmente à Zona de Cisalhamento Mandinópolis (Fig. 2a), em locais de fácil acesso, utilizando-se um GPS Magellan 3000 XL, com precisão espacial de $5 \mathrm{~m}$.

PROCESSAMENTO DOS DADOS AEROGEOFÍSICOS O processamento dos dados acrogeofísicos foi efetuado antes do mapeamento geológico. Para tanto, utilizou-se as insţalações do Laboratório de Geolísica Aplicada (LGA) do Instituto de Geociências da Universidade de Brasília. O processamento de dados ocorreu em meio digital com emprego do programa OASIS Monta Inc. GEOSOFT, (GEOSOFT 1996, 1998). As etapas do processamento de dados estão resumidas na Figura 2.

Os dados aerogeofísicos foram avaliados quanto à presença de inconsistências, como o "efeito pepita" ou "picos", c à distribuição espacial das linhas de vôo. O padrão geral das linhas de vôo não apresentou problemas maiores, exceto os decorrentes de eventuais desvios das mesmas devido ao precário sistema de localização disponível na época. Os dados foram interpolados em malhas regulares, com controle de fidelidade dos dados originais mediante os métodos de curvatura mínima e bi-direcional. A opção final recaiu sobre o método bidirecional devido à melhor preservação das altas freqüências.

O nivelamento convencional dos dados aerogeofísicos, utilizando linhas de vôo transversais às de medida, sempre resulta $\mathrm{em}$ algumas imperfeições na representação espacial dos dados. Para minimizá-los, empregou-se a técnica do micronivelamento (Minty 1991) com algoritmo desenvolvido por Blum (1999).

Os dados aeromagnéticos também foram corrigidos da influência resultante da contribuição geomagnética do núcleo terrestre empregando-se dados do Definitive Geomagnetic Reference Field (DGRF), correspondente a 1975, ano da realização do PGBC. 


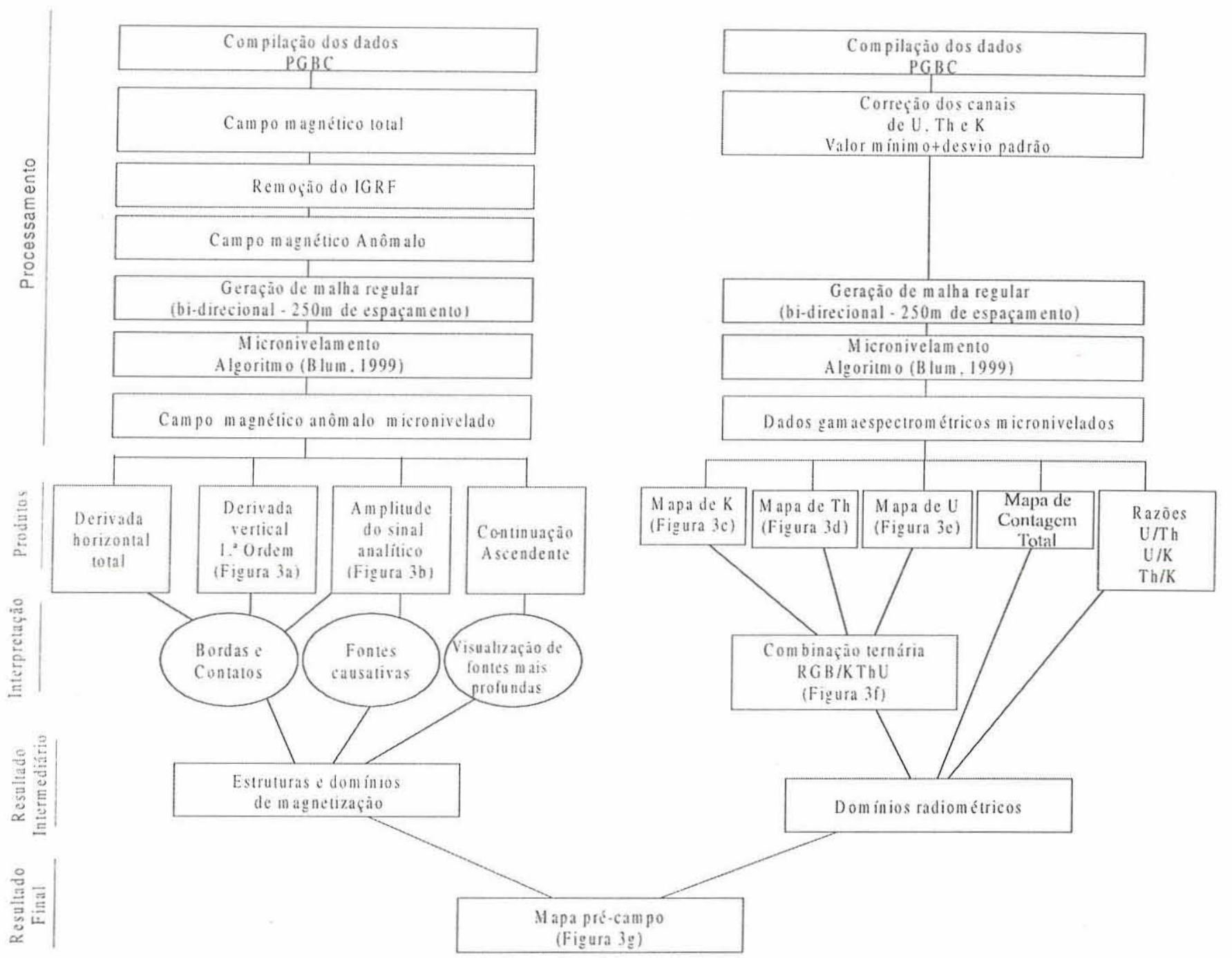

Figura 2 - Etapas de processamento dos dados aeromagnetométricos e acrogamaespectrométricos do PGBC da área mapeada e seu entorno.

INTERPRETAÇÃO DOS DADOS Os dados aerogeofísicos deixaram de ser simplesmente uma ferramenta para trabalhos de cunho geofísico, para se tornarem essenciais no mapeamento geológico de escala regional. A necessidade de interpretar dados desta natureza impulsionou o desenvolvimento de técnicas que seguem caminho semelhante ao empregado na interpretação de fotografias aéreas e os colhidos por sensores remotos (Silva 1999).

No presente caso, os produtos aeromagnéticos consistiram de mapas de campo magnético total, campo anômalo, gradiente horizontal total do campo anômalo, primeira derivada vertical do campo anômalo (Fig. 3a), amplitude do sinal analítico (Fig. 3b) e continuação ascendente do campo anômalo.

Os produtos aerogamaespectrométricos compreenderam imagens dos canais de Potássio (K) (Fig. 3c), Tório (Th) (Fig. 3d), Urânio (U) (Fig. 3e), contagem total e de composição ternária $\mathrm{K}-\mathrm{Th}-\mathrm{U}$ em padrão RGB (vermelho-verde-azul) (Fig. 3f). Da análise dessas imagens resultou o mapa da figura $3 \mathrm{~g}$. O retângulo desenhado sobre todas as imagens define os limites da área posteriormente mapeada.

As imagens geofísicas foram interpretadas simultaneamente ao mapeamento geológico, mediante a correlação dos domínios geofísicos com as unidades estratigráficas maiores, o que permitiu definir os seus limites e sua inserção na estruturação geológica regional. Ainda durante o mapeamento, o levantamento magnetométrico terrestre de seções previamente definidas determinou o posicionamento mais adequado do contato entre os blocos arqueano e proterozóico (Fig. 5), particular- mente em áreas de cobertura de solos mais espessa.

A terceira etapa foi realizada após o mapeamento geológico e consistiu da análise e interpretação de dados de campo, complementados com dados petrográficos e geocronológicos (Jost et al. 2001, Dantas el al. 2001). Todas as informações pré, durante e pós-etapas de campo foram reunidas em um Sistema de Banco de Dados Georeferenciados (SBDG) utilizando o Software ArcView3.2 (ESRI). Após o processamento, as imagens foram exportadas em formato geotif e reunidas no SBDG. Os dados de campo foram uniformizados e inseridos no SBDG por meio do programa Excel (Dbase IV) e continham o número do ponto de observação, latitude, longitude, dados petrográficos, estruturais, geocronológicos, litotipos, etc.

O desenvolvimento das três etapas culminou com a confecção de mapa geológico em escala 1:25.000 (Fig. 5c) e obtenção de um banco de dados digitais com informações de campo, geofísicas, fisiográficas e de imagens processadas do satélite TM-Landsat 5 (Figs. 5a e 6b). O banco de dados permite a atualização e incorporação de novos dados e o exame simultâneo de documentos variados. (Amorim et al. 2002).

Imagens Magnetométricas A análise do campo magnético anômalo foi auxiliada por transformaçōes lineares do mesmo. A delimitação da posição das fontes magnéticas efetuou-se a partir da amplitude do sinal analítico. A extração e caracterização das estruturas magnéticas foram feitas a partir da utilização e interpretação das derivadas vertical e horizontal e a correlação e integração com a geologia local 

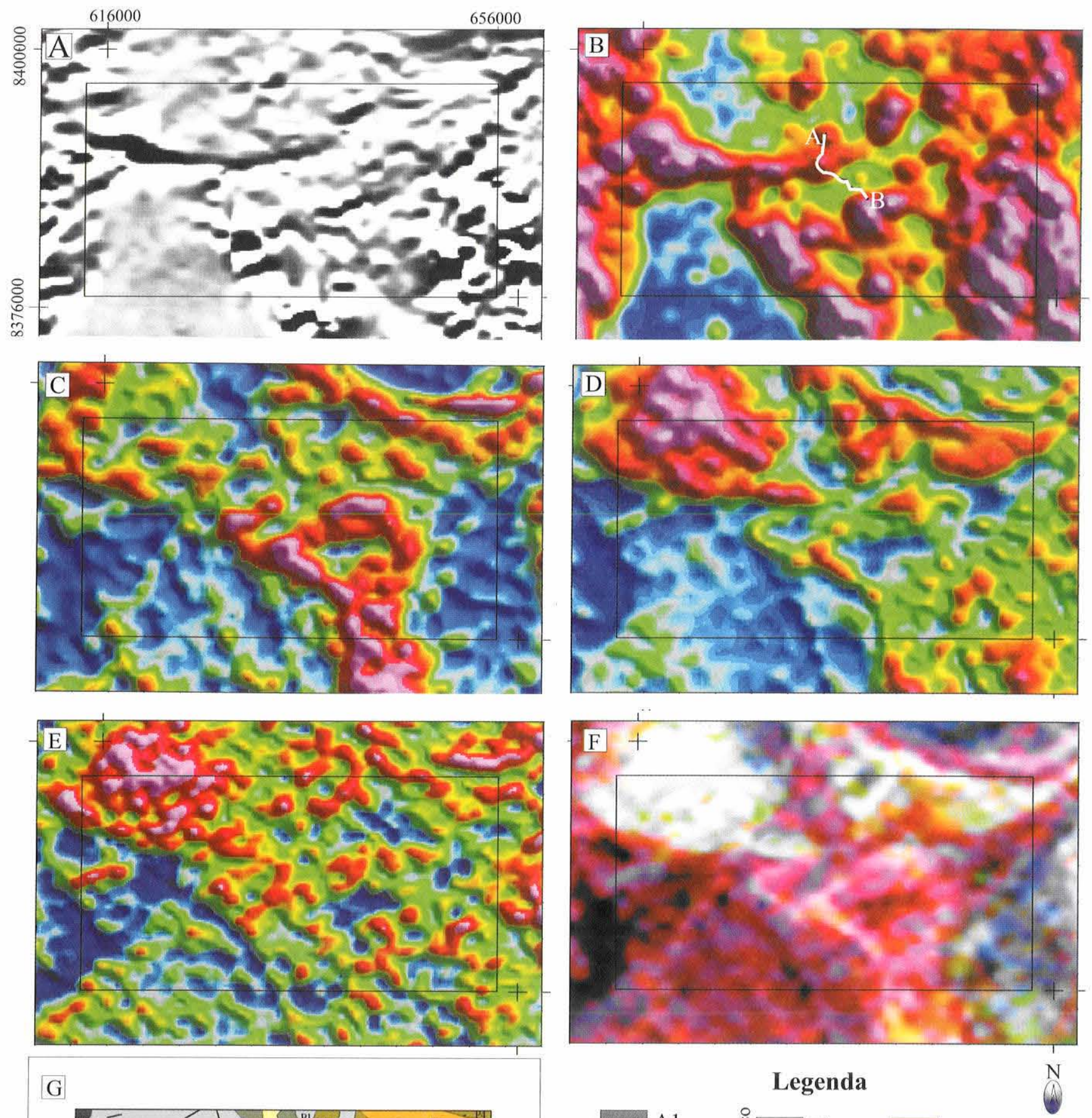

G
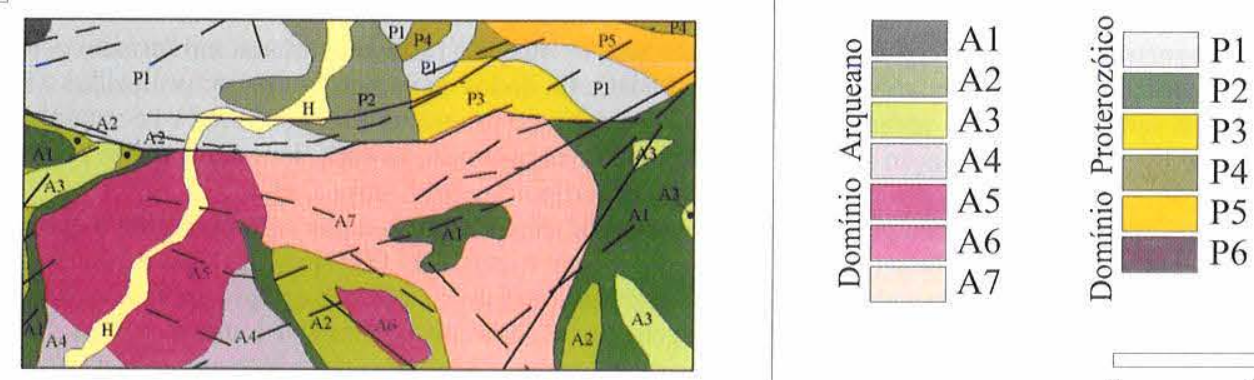

]

Estruturas magnéticas:

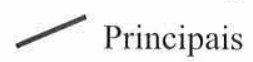

- Secundárias

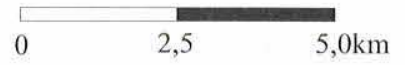

Figura 3 - (a) Mapa da primeira derivada vertical do campo magnético anômalo; (b) Amplitude do sinal analítico do campo magnético anômalo da área mapeada; (c) Imagem do canal do Potássio; (d) Imagem do canal do Tório; (e) Imagem do canal do Urânio; (f) Composicão ternária RGB (K:Th:U); (g) mapa de interpretação integrada baseada nos dados magnéticos e gamaespectrométricos. A escala de valores das imagens $B, C, D$ e E cresce dos mínimos em cor azul escuro aos máximos de cor vermelha. As cores da imagem ternária K/U/Th da figura 3 f resultam de variadas combinaçöes entre os valores representados pelo canais de Potássio. Urânio e Tório. 
(Jost et al. 2001) antes e depois do mapeamento geológico. A interpretação das imagens magnetométricas representadas nas figuras $3 \mathrm{a}$ e $3 \mathrm{~b}$, respectivamente da primeira derivada do campo magnético anômalo c do sinal analítico, mostram com clareza que:

1. na imagem da primeira derivada do campo anômalo (Fig. 3 a), a Zona de Cisalhamento Mandinópolis somente se destaca como contato entre os terrenos proterozóicos e arqueanos na porção ocidental da área mapeada. Para leste, se encurva gradualmente para nordeste quando passa a ser o contato entre as escamas A e B da unidade metavulcânica dos terrenos proterozóicos. Para sudeste c situada apenas em terrenos arqueanos, uma estrutura paralela sc estende a partir do contato do Complexo Caiamar com greenstone belt de Guarinos para nordeste, corta o Bloco Moquém e o greenstone belt de Pilar de Goiás e, daí, para além do vértice nordeste da área;

2. na imagem do sinal analítico (Fig. 3b) a Zona de cisalhamento Mandinópolis pode ser traçada continuamente até o limite nordeste da área, com suave curvatura, destacando-se que a falha de contato entre as escamas A c B da unidade metavulcânica proterozóica é uma derivação da zona de cizalhamento e que a estrutura que, pela imagem da primeira derivada, lhe é paralela e está situada apenas no interior dos terrenos arqueanos lhe é assintótica no extremo nordeste da área;

3. tanto a imagem da primeira derivada (Fig. 3a) quanto a do sinal analítico (Fig. 3b) mostram que, nos terrenos proterozóicos, as rochas de unidade metassedimentar caracterizam por baixos valores de susceptibilidade magnética, em contraste com a unidade metavulcânica, cujos valores são intermediários e, nos terrenos arqueanos, que os rochas do Complexo Caiamar se destacam dos greenstone belts de Crixás e Guarinos. Em ambos casos, os contrastes derivam das reduzidas proporções de minerais magnéticos na unidade metassedimentar e nos tonalitos do completo, comparativamente às rochas metavulcânicas adjacentes.

4. na imagem do sinal analítico (Fig. 3b) também se destaca a pequena área elíptica correspondente a da ocorrência do Trondhjemito Santo Antônio, o qual se distingue claramente do envelope de rochas metavulcânicas máficas do greenstone belı de Guarinos;

5. por fim, as intrusões máficas e ultramáficas do Bloco Moquém respondem por altos valores do sinal analítico (Fig. 3b).

A figura 4 ilustra o campo magnético anômalo e a amplitude do sinal analítico obtidos a partir dos dados magnéticos terrestres levantados no perfil A-B (vide posição na Fig. 3b). O perfil inicia no interior da unidade metavulcânica proterozóica no norte e se estende, para sul, transversalmente à Zona de Cisalhamento Mandinópolis, ingressa no Bloco Moquém, inicialmente em gnaisses granodioríticos e alcança, no extremo sul, gnaisses tonalíticos. O perfil localiza claramente a Cisalhamento Mandinópolis por meio de duas anomalias positivas da amplitude do sinal analítico, com largura aproximada de $400 \mathrm{~m}$, c uma anomalia negativa do campo anômalo. As rochas metavulcânicas proterozóicas apresentam valores de campo magnético anômalo discre- tamente menores que os gnaisses granodioríticos situados imediatamente a sul da zona de cisalhamento e os gnaisses tonalíticos se caracterizam por declínio de valores.

Imagens Gamaespectrométricas As figuras 3c, 3d, 3e, e $3 f$ correspondem às imagens dos canais individuais respectivamente do $\mathrm{K}, \mathrm{Th}, \mathrm{U}$ e da composição ternária colorida RGB (K:Th:U) da área mapeada e seu entorno. A interpretação das imagens com vistas ao mapeamento de domínios gamaespectrométricas foi inicialmente realizada por comparação entre as correspondentes a cada canal (CT,K, U, e Th); seguida da análise da imagem ternária $(K, U, T h)$ RBG e CMY. As razões $\mathrm{U} / \mathrm{Th}$, Th/K e U/K não mostraram resultados significativos definição de domínios.

A imagem do canal do Potássio (Fig. 3c) mostra valores homogêneos na maior parte da área mapeada. Contudo, esta destaca os baixos valores correspondentes aos greenstone belts de Crixás, Guarinos e de Pilra de Goiás, às do Complexo Caiamar e à maioria das rochas metavulcânicas proterozóicas, todas em tons de azul ou verde, resultante das baixas proporções de Potássio nestas rochas. Contudo, em meio aos baixos valores de Potássio sobressaem pelo menos quatro feições que controlam valores altos (cor amarela ou vermelha). Estas compreendem:

1 - a área de ocorrência dos gnaisses granodioríticos e tonalíticos do Bloco Moquém em cujo interior há uma zona alongada que corresponde a nicho de intrusões máficas e ultramáficas,

2 - a Zona de Cisalhamento Mandinópolis pelo rosário de anomalias de potássio alinhadas segundo E-W, prováveis zonas de alteração hidrotermal mais intensa;

3 - zonas de anomalia estreita curvas no vértice nordeste da área, corresponde a metavulcânicas felsicas proterozóicas c

4 - subordinadamente, anomalias alinhadas SW-NE no Complexo Caiamar que sugerem lineamentos com concentrações de veios pegmatóides, também evidentes na imagem de composição ternária K/U/Th (Fig. 3f).

A imagem do canal do Tório (Fig. 3d) repete os baixos valores correspondentes aos greenstone belts de Crixás e Guarinos e ao Complexo Caiamar, apesar do contraste litológico entre as supracrustais e o complexo. Contudo, os baixos valores destes se distinguem dos intermediários correspondentes ao Bloco Moquém, por sua vez indistintos do greenstone belt de Pilar de Goiás. O contraste do Bloco Moquém resulta da maior afinidade do Th com granodioritos do que com tonalitos e rochas vulcânicas máficas e ultramáficas, respectivamente do Complexo Caiamar e dos greenstone belts. Por outro lado, o baixo contraste entre o Bloco Moquém e o greenstone belt de Pilar de Goiás é, provavelmente, devida à abundância de injeções tabulares de granitóides ao longo de zonas de cisalhamento que ocorrem nas proximidades dos dois domínios, mas concentradas nas supracrustais. Nesta imagem novamente se destaca a zona de intrusões máficas e ultramáficas do Bloco Moquém, marcado por mancha azul que retrata baixos valores de Tório em meio aos gnaisses.

Por outro lado, no segmento proterozóico, a unidade

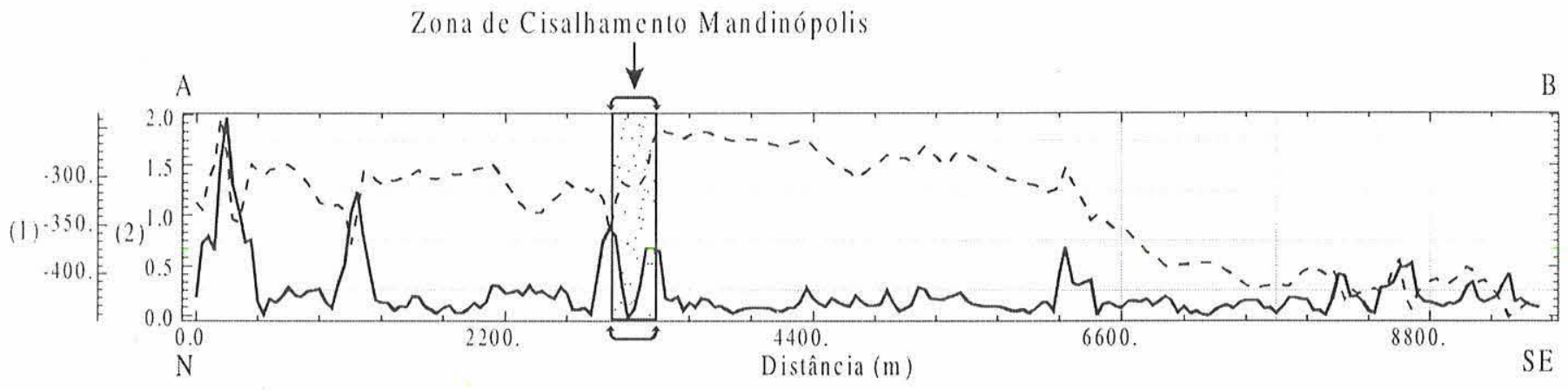

-- C. Campo Magnético Anômalo em nanoTesla (1) __ Amplitude do Sinal Analítico em nanoTesla por metro (2)

Figura 4-Perfil magnético terrestre transversal à Zona de Cisallamento Mandinópolis em posição mostrada na figura 3. Escalas: (1) - campo magnético anômalo em nano Tesla e (2) - amplitude do sinal analítico, em namoTesla por metro. 

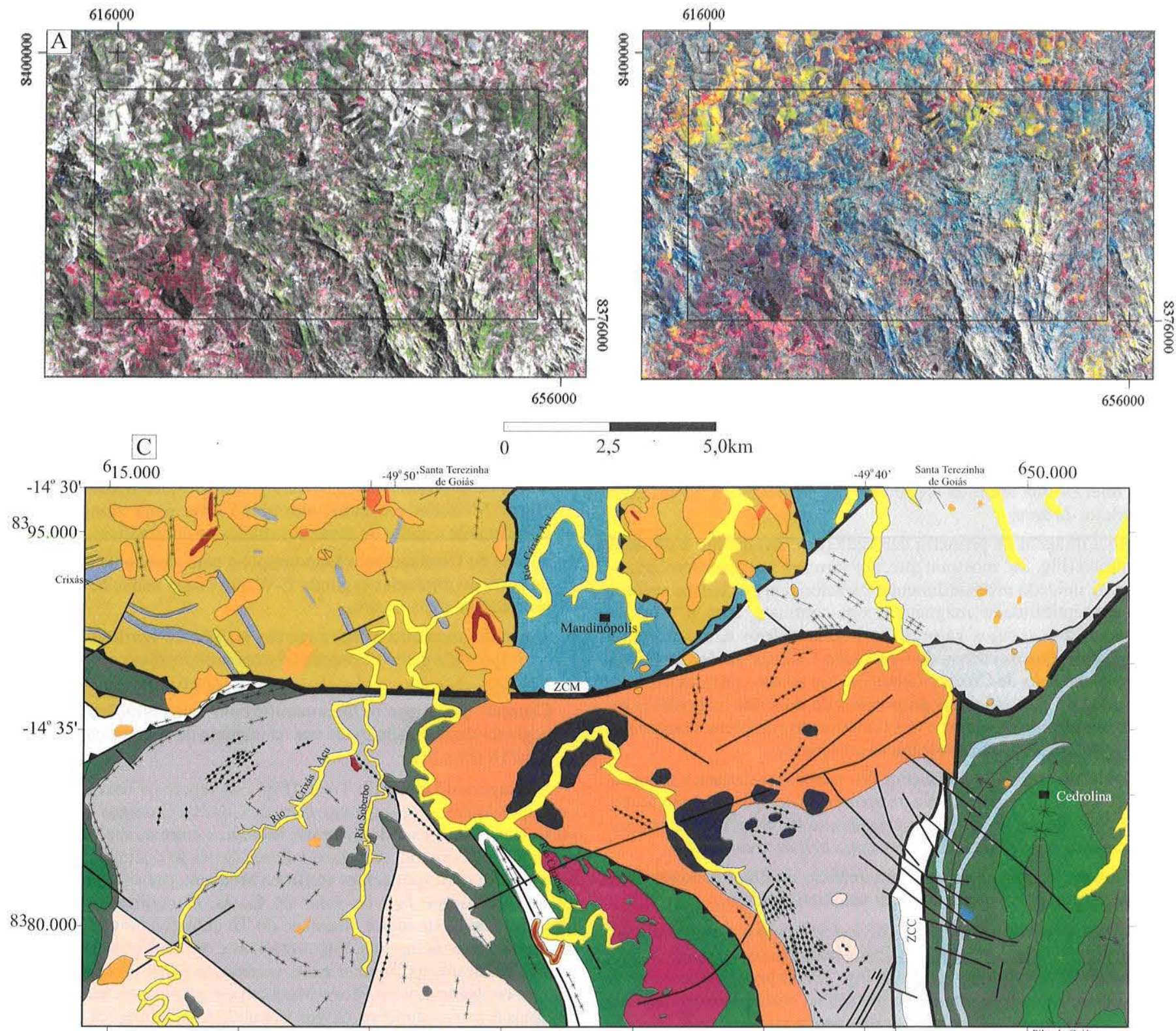

Legenda

CENOZÓICO

Depósitos aluviais

Crosta ferruginosa

Paleopavimento detrítico

Unidade metassedimentar $\quad\left\{\begin{array}{l}\text { Metatonalito } \\ \text { Quartzo-mica xistos }\end{array}\right.$

PROTEROZÓICO

$\begin{array}{lll} & \text { Quartzito } \\ \text { Escama A } ~ & \text { Anfibolitos, anfibólio xistos, BIF, metapelitos }\end{array}$

Unidade metavulcânica $\{$ Escama B $\square$ Magnetita-clorita xistos, ortognaisses

Escama C $\square$ Clorita xistos, metapsamitos, metapelitos

$\square$ Trondhjemito Santo Antônio

\begin{tabular}{|c|c|c|}
\hline Bloco Moquém & $\square$ & $\begin{array}{l}\text { Stocks tonaliticos } \\
\text { Intrusões máficas } \\
\text { Intrusões ultramáficas } \\
\text { Gnaisses granodiorític } \\
\text { Gnaisses tonalíticos }\end{array}$ \\
\hline nplexo Caiamar & & $\begin{array}{l}\text { Gnaisses Crixás Açu } \\
\text { Tonalito Tocambira }\end{array}$ \\
\hline
\end{tabular}

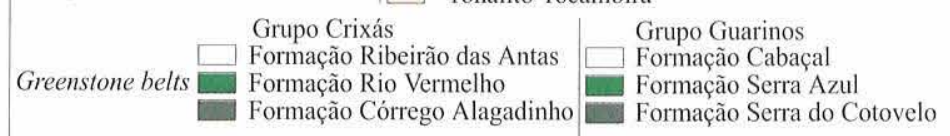

$-49^{\circ} 40^{\circ} \quad$ Santa Terezinhas $\quad 650.000$ 
Tabela I-Características geofísicas interpretadas de cada unidade da Figura $3 g$.

\begin{tabular}{|c|c|c|c|c|c|}
\hline Domínio & Unidade & Potássio & Tório & Urânio & Magnetismo \\
\hline \multirow{7}{*}{ 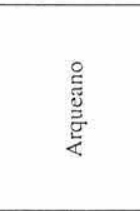 } & Al & baixo & baixo & baixo & alto \\
\hline & $\mathrm{A} 2$ & alto & baixo & baixo & médio \\
\hline & $\mathrm{A} 3$ & alto & baixo & médio & variável \\
\hline & A4 & médio & baixo & alto & baixo \\
\hline & A5 & baixo & baixo & médio & baixo \\
\hline & $\wedge 6$ & alto & baixo & médio & baixo \\
\hline & A7 & alto & baixo & variável & baixo \\
\hline \multirow{6}{*}{ 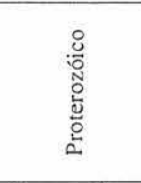 } & $\mathrm{Pl}$ & alto & alto & variável & baixo \\
\hline & P2 & baixo & baixo & alto & variável \\
\hline & P3 & médio & baixo & alto & variável \\
\hline & $\mathrm{P} 4$ & baixo-médio & baixo & variável & variável \\
\hline & P5 & médio-alto & baixo-médio & variável & variável \\
\hline & P6 & médio & baixo & alto & baixo \\
\hline Fanerozóico & $\mathrm{H}$ & alto & médio & variável & variável \\
\hline
\end{tabular}

metassedimentar claramente se destaca da metavulcânica pelos valores elevados de nos canais do Th e U (Figs. 3d e 3e), diferença esta tambéwm retratada na imagem ternária RGB da figura $3 \mathrm{f}$. Nas ctapas precedentes ao mapeamento, a origem das anomalias do canal do Th foi atribuída à provável espessura da cobertura de solos com crostas lateríticas da superfície de aplainamento sustentada pelo segmento proterozóico. Durante o mapeamento observou-se que as crostas ferruginosas somente ocorrem como resíduos ao longo das cotas mais elevadas do relevo suavemente ondulado do domínio desta unidade e, em geral, o solo típico destas rochas é saprólito de espessura centimétrica, localmente métrica. Assim, a assinatura da unidade no canal do Th pode ser atribuída, originalmente, à rocha fresca. Isto pode ser explicado se o protólito do mica-quartzo xisto dominante for interpretado como pelito resultante do intemperismo e erosão de área-fonte dominada por illita, para explicar a abundância de muscovita. Segundo Jost et al. (1996) e Resende et al. (1999), argilo-minerais do grupo da ilita representam estágios avançados de intemperismo químico c devido à baixa mobilidade do Th espera-se que sua concentração, na forma adsorvida em argilo-minerais, aumente nos estágios mais avançados do intemperismo. Assim, a anomalia de Th nessas rochas deve-se, provavelmente, à abundância de muscovita, com parcial reconcentração no saprólito e restos de crosta ferruginosa, com cujos óxidos o elemento também tem afïnidade. O mesmo raciocínio pode ser aplicado ao Urânio, o que justifica os valores observados na unidade metassedimentar no canal deste elemento.

No que tange à unidade metavulcânica, a escama $\mathrm{A}$, composta por anfibólio xistos e anfibolitos, é reconhecível na porção centro-norte da área pelos baixos valores nos canais do Potássio e do Tório, comparativamente às demais escamas, de clorita xistos e magnetita-clorita xistos com eventuais intercalações de rochas félsicas. Estas, no entanto, predominam no vértice nordeste da área e onde claramente se manifestam, no canal do Potássio, pelos valores elevados dispostos em estreita faixa curva e concavidade voltada para nordeste.

Por fim, imagem ternária RGB composta dos valores dos canais do U, Th e K (Fig. 31) não distingue, no segmento arqueano, os greenstone belts de Crixás e Guarinos e o Complexo Caiamar entre sí. Mas destaca o Bloco Moquém, incluindo a posição das intrusões máficas e ultramáficas da sua porção centro-norte, e o geenstone belt de Pilar de Goiás. A mesma imagem nitidamente mostra o limite curvo do contato entre o segmento proterozóico, a norte, e arqueanos, a sul, estabelecido pela Zona de Cisalhamento Mandinópolis. No domí- nio proterozóico, as tonalidades mais claras, dadas pelo canal do Tório, correspondem às duas áreas de ocorrência da unidade metassedimentar. Destaque-se que os claros limites da unidade metassedimentar situada em posição centro-norte da área mapeada e sua desconexão com a de oeste permite sugerir que a mesma repousa sobre a unidade metavulcânica como klippe. Ademais, ambas áreas estão separadas por faixa de tonalidade vermelha intensa, a qual corresponde aos anfibolitos e anfibólio xistos da escama A. Para leste, é nítida a extensão da escama $\mathrm{B}$ e da $\mathrm{C}$ na área mapeada.

\section{INTEGRAÇÃO DOS DADOS E DISCUSSÕES FINAIS}

Grande parte dos terrenos proterozóicos na área mapeada sustentam extensa superfície de aplainamento com cobertura edáfica que, ainda que rasa, pouco expõe o substrato rochoso, comumente expresso em regolitos composicionalmente variados. Em contraste, a Zona de Cisalhamento Mandinópolis e as unidades arqueanas estão bem expostas em toda área do mapeamento, mas nem sempre os seus limites são nítidos. Em vista das características fisiográficas da região, a geração de imagens, em escala adequada, a partir de dados magnetométricos e gamaespectrométricos e sua intepretação prévia foram de utilidade substancial durante o mapeamento geológico subsequente.

Isles et al. (1990) sugerem que a escala ideal para compilar dados aerogeofísicos é de $1 \mathrm{~cm}$ no mapa seja aproximadamente equivalente ao espaçamento entre as linhas de vôo. Segundo esta premissa, a escala ideal para a área estudada é de 1:100.000, utilizada durante os trabalhos de laboratório que antecederam o mapeamento (Silva 1999). Contudo, para melhor subsidiar o mapeamento geológico, procedeu-se à ampliação das imagens para a escala 1:25.000, utilizada durante os trabalhos de campo. Em trabalhos com dados magnéticos, este procedimento não apresenta problemas significativos. Entretanto, este procedimento aplicado a dados gamaespectrométricos tende a gerar imagens de baixa resolução espacial, o que não se verificou neste exercício $\mathrm{em}$ particular, pois diversas unidades mapeadas na escala 1:25.000 foram discriminadas pelos dados radiométricos. $\mathrm{O}$ mapa da figura $3 \mathrm{~g}$ retrata a distribuição de unidades geofísicas distribuídas conforme a respectiva legenda e detalhadas na Tabela 1 , complementado com elementos estruturais intepretados a partir imagens TM Landsat 5 (Fig. 5a e 5 b), o conjunto agrupado $\mathrm{em}$ banco de dados georreferenciados (SBDG). O mapa geológico resultante de trabalhos de campo (Fig. 5c) mostra que a carta de integração de dados geofísicos (Fig. $3 \mathrm{~g}$ ) foi modificada apenas $\mathrm{em}$ detalhes, particularmente no domínio proterozóico, mas, mesmo assim, com discriminação de unidades até então não registradas. Isto mostra, por seu turno, que levamentos aerogeofísicos antigos, tais como o do PGBC, não devem ser descartados e, na medida do possível, integrados para subsidiar a trabalhos de escopo regional.

Agradecimentos À Companhia de Pesquisa c Recursos Minerais - CPRM e ao departamento Nacional de Produção Mineral DNPM, pela cessão e permissão da uso dos dados do PGBC em trabalhos de pesquisa do LGA (Laboratório de Geolísica Aplicada) - IG UnB. A segunda autora agradece a Msc. Cláudia Arantes e os Professores Augusto César Bittencourt Pires e Roberto Alexandre Vitória de Moraes pelo suporte durante o processamento e intepretação dos dados estudados na disciplina Introdução ao Processamento e Interpretação de Dados Aerogeofísicos. A dois revisores anônimos da RBG pela revisão e sugestões ao original e ao CNPq pelas bolsas de produtividade a H. Jost e R.A. Fuck.

\section{Referências}

Amorim A.T. Lima B.E.M., Silva A.M., Silva A.A.C., Jost H., Meneses P.R.. 2002. O uso de geoprocessamento para mapeamento geológico: A experiência da graduação da

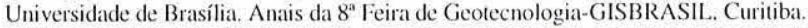

Blum M.L.B. 1999. Processamento E Interpretafão De Dades De Geofisica Aérea No Brasil Central E Sua Aplicaşão À Geologia Regional E À Prospeção Mineral. Instituto de Geociências. Universidade de Brasília, Brasília, Tese de Doutoramento, $229 \mathrm{p}$.
Carmo, S.D. 1978. Programação e execução do Projeto Geofísico Brasil-Canadá. In: CONGR. BRAS. GEOL., 30, Recife, 1978. Anais... Recife, SBG. v.5. p. 2233-2247.

Dantas E.L.. Jost H., Brod J.A., Fuck R.A., Pimentel M.M., Meneses P.R. 2001. Proveniência e idade deposicional de sequiências metavulcano-sedimentares da região de Santa Terezinha de Goiás. Goiás, baseada em dados isotópicos de U-Pb em monocristal de zircāo e Sm-Nd. Revista Brasileira de Geociências. 31:

DNPM 1981. Projéto Géofísico Brasil-Canadá: histórico e atividades até 30/09777. MME/ DNPM, Goiânia, GSC, Canadá. 
GEOSOFT 1996. MAGMAP 2-D frequency domain processing. GEOSOFT, Inc., Toronto. GEOSOFT 1998. OASIS Montaj 4.2. GEOSOFT, Inc., Toronto.

Isles D.J., Cooke A.C.. Hallberg J.A. 1990 . Aeromagnetic evaluation. In: S.E. Ho, D.I. Groves, Bennett, J.M. (eds.) Gold Deposits of the Archaean Ylgam Block, Westem Australia. Australia, Geology Key Centre \& University Extension, University of Western Australia, Department of Geology, Publication 20, 342-347.

Jaques A., Wellman P., Wyborn D. 1997. High-Resolution Geophysics In Modern Geologic Mapping. Asgo Journal Of Australian Geology \& Gerphysics, 17:159-173.

Jost H.. Fuck R.A.. Brod J.A., Dantas E.L., Meneses P.R. Assad M.L.L.. Pimentel M.N. Blum M.L.B..Silva A.M.. Spigolon A.L.D., Maas M.V.R.. Souza M.M... Fernandez B.P. Faulstich F.R.L. Macedo Júnior P.M.. Schobbenhaus C.N.. Almeida L... Silva A.A.C., Anjos C.W.D.. Santos A.P.M.T., Bubenick A.N.. A.A.A Teixeira, Lima B.E.M.. Campos M.O.. Barjud R.M.. Carvalho D.R.. Scislewski L.R., Sarli C.L.. Oliveira D.P.L. 2001. Geologia de terrenos arqueanos e proterozóicos da regiî̀o de Crixás-Cedrolina, Goiás. Revista Brasileira de Geociências, 31:

Jost H., Theodoro S.M.C.H., Figueiredo A.M.G., Boaventura G.R. 1996. Propriedades geoquímicas e proveniência de rochas metassedimentares detríticas arqueanas dos greenstone belts de Crixás e Guarinos, Goiás. Revista Brasileira de Geociêncius. 26:151-166

Minty B.R.S. 1991. Simple Micro-Levelling for Aeromagnetic Data. Expl. Geoph. 22:591. 592.

Resende M.G. Jost H.. Lima B.E.M., Teixeira A.A. 1999. Proveniência e didades modelo $\mathrm{Sm}-\mathrm{Nd}$ das rochas siliciclásticas arqueanas dos greenstone belts de Faina e Santa Rita, Goiás. Revista Brasileira de Geociências, 29:281-290

Silva A.M. 1999. Integrasäo de dados geológicos e geofísicos utilizando-se uma nova técnica estatistica para selesäo de alvos para explorascáo mineral. aplicada as Greenstome belt Rio das Velhas, Quadrilátero Ferrifero. Instituto de Geociências, Universidade de Brasília, Brasília, Tese de Doutoramento, 195p.

Manuscrito A-1179

Recebido em 31 de julho de 2001 Revisão dos autores em 25 de agosto de 2001 Revisão accita $\mathrm{cm} 30$ de agosto de 2001 